\title{
MOBILE-ASSISTED SECOND LANGUAGE LEARNING: SPEAKING A SECOND LANGUAGE WITH AUDITORY STIMULI
}

\author{
Choy Khim Leow ${ }^{1}$ \\ Wan Ahmad Jaafar Wan Yahaya ${ }^{2}$ \\ Mariam Mohammad ${ }^{3}$ \\ Centre for Instructional Technology \& Multimedia, Universiti Sains Malaysia, 11800 \\ Penang, Malaysia. \\ Songhao $\mathrm{Liu}^{4}$ \\ School of Chinese as a Second Language, Peking University \\ ${ }^{1}$ choy_khim@yahoo.com \\ ²wajwy@usm.my \\ 3mmohamad@usm.my \\ ${ }^{4}$ songhaol@pku.edu.cn
}

\begin{abstract}
Research on Mobile-Assisted Language Learning (MALL) has mostly focused on investigating the effectiveness and physical nature of mobile technology or the psychological conditions of learners. Studies of MALL that associate the fundamental principles of the human cognitive learning process is comparatively less common. Despite years of formal instruction, speaking a second language remains a challenge for beginner learners of Chinese as a Second Language (CSL) in Malaysian International Schools. To help explain this, a framework of Mobile-Assisted Second Language Learning (MASLL) is developed to explain the cross-channel mental representation process in acquiring the speaking skills of a second language, using mobile phones. A total of 30 middle-year school learners from Malaysian International Schools underwent a quantitative, quasi-experimental pilot study. Learners with only the auditory stimuli outscored learners with the auditory-visual stimuli, with a mean difference of 4.87 in the gain scores. Whilst recognising the importance of auditory-visual stimuli during the learning phase, these findings highlight the importance of activating cross-channel mental representation during the interface and acquisition phases. A larger sample is needed to further validate these findings. Future studies on neuroscience, which localise the brainwave analysis, will be useful in providing visual explanation of the human cognitive processes and memory coding in acquiring the speaking skills of a second language.
\end{abstract}

Keywords: mobile-assisted language learning, second language acquisition, speaking, auditory visual stimuli, information processing, multimedia learning 


\section{Introduction}

Research on learning a second language (L2) with mobile devices has shown its effectiveness, but most of these studies have focused on investigating the effectiveness (Al-Jarf, 2012; Demouy \& Kukulska-Hulme, 2010) and effects on motivation levels of mobile technology users in enhancing Second Language Acquisition (SLA) (Kinash, Brand, \& Mathew, 2012; Wang \& Wang, 2009). However the fundamental understanding of the cognitive processes of $L 2$ learners when using the multimedia presentation (also called "multimedia learning") through mobile phones is less studied. Multimedia learning refers to learners' construction of knowledge through building the mental representations (Mayer, 2014).

Knowledge construction for SLA however requires a different approach when compared with first language (L1) acquisition. Though L1 and Second language (L2) acquisition share some similarities; other differences from the aspects of neurological, psychomotor and affective considerations are important as they can provide useful information to aid language teachers in their profession (Ipek, 2009). The phenomenon of learners of Chinese as a Second Language (CSL) not being able to use the target language (TL) even after years of formal instruction in school (Leow, Wan Ahmad Jaafar, \& Samsudin, 2014a) has been a major concern for L2 teaching in Malaysia.

Hence a framework of Mobile-Assisted Second Language Learning (MASLL) associating the SLA theories with mobile learning has been developed to explain the mental representation process when learning to speak a L2 with mobile technologies. Findings from the pilot study show the feasibility of the MASLL model as well as the positive implications of auditory stimuli versus auditory-visual stimuli.

\section{Literature Review}

\section{Speaking a Second Language: The Teaching and Learning}

There has been an increase in demand for learning a $L 2$ in schools around the world. The importance of second language teaching and learning has been reflected by the fact that learning two foreign languages for at least one year during compulsory education is an obligation for all pupils, between 10-15 years old, in the majority of European countries. Furthermore, $80 \%$ of the students in these countries expressed the view that the learning of foreign languages is for the purpose of future work, and getting a good job (ESLC, 2012). Malaysia in particular, despite its multicultural and multilingual environment, has highlighted the importance of being proficient in third language for human capital development (Malaysian Ministry of Higher Education, 2007).

The introduction of CSL or BCK (Bahasa Cina Kebangsaan) to 14,298 students in 153 Malaysian national schools signifies the importance of acquiring Chinese Mandarin language from the elementary to secondary school level. Research on Chinese listening and speaking however remains limited to date (Jiang \& Cohen, 2012). Findings from Leow, Wan Ahmad Jaafar and Samsudin (2014b) have raised the teaching and learning dilemma encountered by the Malaysian International 
Schools' learners and teachers; the CSL learners are not able to use the TL for daily communication despite years of formal instruction. Reasons confirmed from the semi-structured interviews indicate that the complexities of the Chinese language (reading and writing skills), the exam-driven learning targets and the lack of opportunities for practical usage of the TL in context, are the major hurdles for teachers and learners. Hence, the teaching and learning approaches for CSL remain focused on drilling learners for reading and writing skills, Leow et al. (2014a), explained further.

When asked about their readiness to adopt mobile phones for teaching and learning in school, both teachers and learners expressed their interest in exploring it (Leow et al., 2014b). The e-learning environment as a whole is encouraging; the annual report shows $100 \%$ of Malaysian schools were connected up to $10 \mathrm{Mbps}$ Internet for e-learning purposes (Malaysian Communication and Multimedia Communication, 2013). In addition, the number of school learners in the age group 15-19 using the internet for learning is comparatively high, making up the 4th highest group at $10.7 \%$ of the total users (Malaysian Communication and Multimedia Communication, 2014).

\section{Applications of Speaking Technologies}

In regards to the mobile technologies, the available educational online applications or software for L2 speaking is scarcely found; some are stand-alone apps for learning to pronounce, recording voice for homework submission, voice email, podcasts, text-to-speech software etc. In other words, they are designed to provide audio or sound input; some encourage output, yet voice interactions are significantly not available at the moment. The Task-Based Language Teaching (TBLT) approach, which focuses on the speaking skills acquisition, has yet to be developed in the mobile application industry. Table 1 illustrates an overview of applications for mobile phones, desktop/tablet software.

Table 1

An overview of application for speaking skills acquisition

\begin{tabular}{|c|c|c|c|c|}
\hline $\begin{array}{l}\text { Language } \\
\text { Skills }\end{array}$ & $\begin{array}{l}\text { Mobile Phone } \\
\text { Application }\end{array}$ & $\begin{array}{l}\text { Online } \\
\text { Software }\end{array}$ & $\begin{array}{l}\text { Stand-alone } \\
\text { application }\end{array}$ & $\begin{array}{l}\text { Interaction } \\
\text { Application }\end{array}$ \\
\hline Listening & 9 & 0 & \multirow{4}{*}{20} & \multirow{4}{*}{0} \\
\hline Speaking & 1 & 0 & & \\
\hline Reading & 8 & 13 & & \\
\hline Writing & 2 & 7 & & \\
\hline
\end{tabular}

Other Computer-Mediated Communication (CMC) such as Whatsapp, WeChat, Viber, Kakao and FaceTime have largely been used for L2 or foreign language teaching and learning. CMC has become the trend in foreign language teaching (Xie \& Yao, 2012); MSN Messenger, Yahoo Messenger, Skype, AIM, and QQ have also been used for online tutoring and teaching (Godwin-Jones, 2005). 
This asynchronous mobile technology, from text-based online chat to current voice messaging has provided subtle potential for L2 learning opportunities. Many studies have shown the effectiveness of MALL in developing L2 vocabulary, grammar and reading skills (Basoglu \& Akdemir, 2010; Cavus \& Ibrahim, 2009; Chang \& Hsu, 2011; Choi \& Jeong, 2010; Lu, 2008; Wu, Sung, Huang, Yang, \& Yang, 2011).

As far as L2 speaking skills are concerned, Kongkerd (2013) highlighted that speaking skills can be acquired through creating a context of language, which involves both a real and virtual communicating environment. Hence the approach of TBLT in Communicative Language Teaching (CLT) is employed to maximise the speaking opportunities in classroom learning.

\section{Meta-Analysis and Systematic Review on MALL}

The systematic review shows that amount of research on MALL conducted in Malaysia is relatively small and the samples were mainly taken from university students and adults. Studies on SLA concentrated heavily on English language learning, and less on Chinese as a Second Language (CSL) learning, particularly in Malaysia.

\section{The Auditory Stimuli for Speaking Acquisition}

Various studies have seen the effectiveness of applying an auditory input approach, by using MP3s and Ipods (Al-Jarf, 2012; Demouy \& Kukulska-Hulme, 2010) and podcasts (Abdous, Camarena \& Facer, 2009; Hegelheimer \& O'Bryan, 2009) when learning a $\mathrm{L} 2$. Hence the auditory stimuli is proposed in this study.

The auditory stimuli principle is derived from the three assumptions postulated by Mayer (2009) in his Cognitive Theory of Multimedia Learning. The two goals of multimedia learning by Mayer are remembering and understanding. This study however extends the investigation to the acquisition phase, from the perspective of SLA. The three assumptions (dual channels, limited capacity and active processing) were employed when designing the content for the learning phase of the $L 2$

However, extending from the phase of learning phase are the phases of interface phase and acquisition phase. The effects of articulatory suppression in the phonological loop posited by Baddeley (2000) are the main factors to consider, as they highlight the role of the articulatory rehearsal system by giving the following typical example: performance in reciting the irrelevant words declines markedly, if subjects are prevented from rehearsing the items to be remembered. This explains the importance of having auditory output (rehearsing) in order to prevent the decay of auditory memory, and to increase the speed of acquisition of foreign language vocabulary in adults (Baddeley \& Hitch, 2000).

The subsequent Paivio's dual-channel assumption (verbal and non-verbal) further supports the existence of a cross-channel mental representation from both sensory modes: the auditory and visual stimuli. The limited-capacity assumption to process information in each channel (Sweller, 2005; Sweller \& Chandler, 1991, as 
cited in Mayer, 2009) is suffice to explain the rationale of having only auditory stimuli when the purpose of $L 2$ learning is to acquire the speaking skills.

Hence, the auditory stimuli are able to enhance the acquisition of the speaking skills of a $L 2$, in other words to be able to speak the $T L$ in a fluent manner and achieve some extent of accuracy (the specifications for this study). Visual-audio stimuli however will compete for cognitive processing in the limited capacity of the human processing system (particularly for beginners of a L2), which then slows down the development of speaking skills of a $L 2$.

\section{The Development of MASLL Framework}

It is central to understand the SLA processes, in order to facilitate the design of L2 instruction in a MASLL environment. The development of the MASLL framework stems from the investigation of $L 2$ speaking acquisition, from the perspective of the information processing system, as depicted in Figure 1.

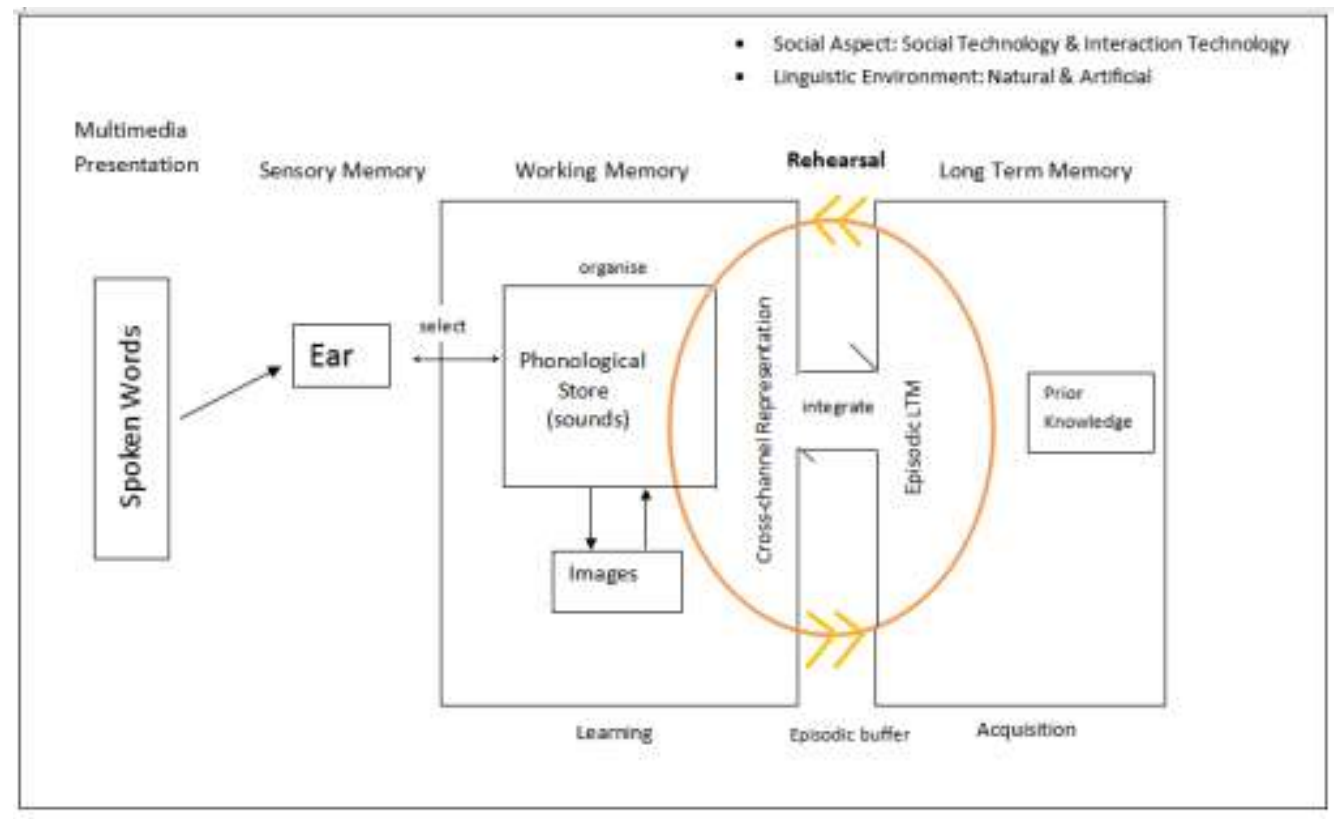

Figure 1. Theoretical framework for Speaking a Second Language

MASLL framework adapts theories, model and principles from the field of SLA, multimedia learning and mobile education in order to provide a scientific and empirical base when designing the framework. Nation's (2007) Four Strands of Language Learning, Mayer's (2009) Cognitive Theory of Multimedia Learning, and Koole's (2009) Framework of Rational Analysis of Mobile Education are the three major models for understanding the L2 acquisition in a mobile learning environment. 


\section{Nation's Four Strands.}

Nation's (2007) Four Strands is a language learning principle, which emphasises the importance of achieving balance opportunities across meaning-focused input, meaning-focused output, language-focused learning, and fluency development. The illustration of Four Strands is shown in Table 2.

Table 2

Nation's (2007) Four Strands for Language Learning

\begin{tabular}{cccc}
\hline \multicolumn{3}{c}{ Meaning-Focused Strands } & $\begin{array}{c}\text { Language-Focused } \\
\text { Strand }\end{array}$ \\
\hline $\begin{array}{c}\text { Meaning-Focused } \\
\text { Input }\end{array}$ & $\begin{array}{c}\text { Meaning-Focused } \\
\text { Output }\end{array}$ & $\begin{array}{c}\text { Fluency } \\
\text { Development }\end{array}$ & $\begin{array}{c}\text { Language-Focused } \\
\text { Learning }\end{array}$ \\
\hline Listening & Speaking & $\begin{array}{c}\text { Receive } \\
\text { Message }\end{array}$ & Short-term \\
\hline Reading & Writing & $\begin{array}{c}\text { Convey } \\
\text { Message }\end{array}$ & Long-term \\
\hline
\end{tabular}

According to Nation (2007), each strand should have roughly the same amount of time to cover both receptive and productive skills; and these have to take account of the learning in the classroom and the language learning that occurs outside the classroom. The roughly equal amount of time is justified by two principles postulated by Ellis (2005): (1) instruction needs to ensure that learners focus predominantly on meaning; (2) instruction needs to ensure that learners also focus on form.

This study highlights the meaning-focused output strands, by which it supports and pushes learners to produce spoken output in a variety of appropriate genres - an initiative taken following findings from the preliminary investigation (Leow et al., 2014a). Learners of CSL in Malaysian International Schools need to be pushed to produce the spoken output, and support should always be provided. On the other hand, the pushed input and search input are suggested for large quantities of comprehensible input (Nation, 2007).

\section{Mayer's Cognitive Theory of Multimedia Learning.}

This study taps into the central idea of Mayer's multimedia learning where words and pictures enable learners to learn deeper than words (Mayer, 2014), but defines the learning and acquisition phases differently from SLA perspective. Mayer focuses on the sensory memory, with auditory stimuli being the investigated variable in this study.

The MASLL framework is developed by drawing from the three assumptions underpinning the Cognitive Theory of Multimedia Learning: (1) the dual channels (Baddeley, 1992; Paivio, 1986); (2) limited capacity (Baddeley, 1992; Chandler \& Sweller, 1991) and (3) Active Processing (Mayer, 2009). 
The corresponding cognitive processing system (selecting, organising, and integrating) and memory stores (sensory memory, working memory and long-term memory) are adapted into the framework, from the perspective of the sensory memory.

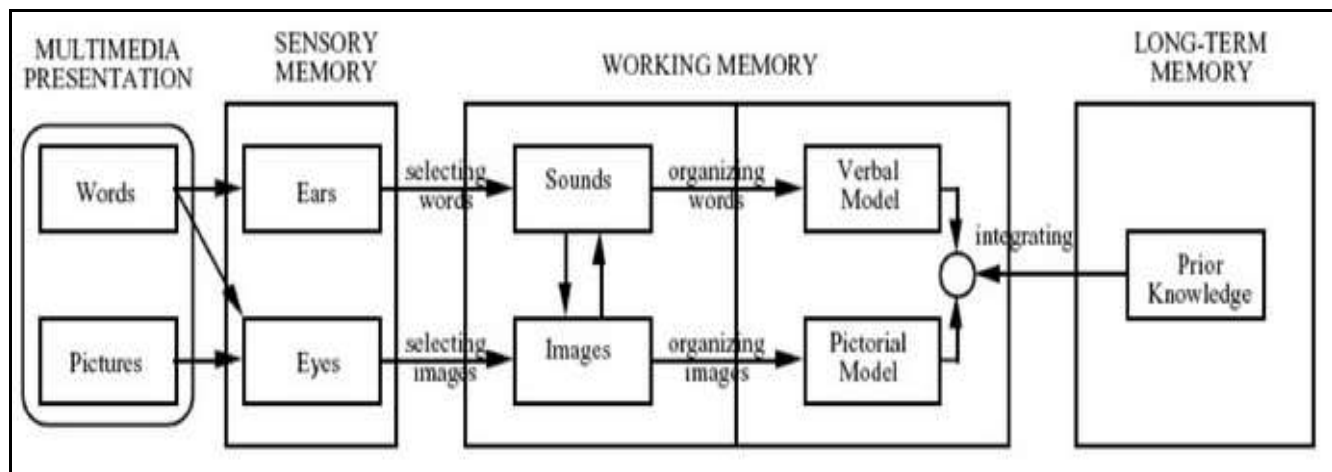

Figure 2. Cognitive Theory of Multimedia Learning

The study of L2 speaking acquisition focuses on sensory-motor-training in the phonological loop, hence the rehearsing approaches in the auditory channel are important for automaticity attainment, and for the cross-mental representation (images) that occur in the working memory.

\section{Mobile Education.}

Studies on mobile learning (m-learning) are still in their embryonic stage. This study employs the Framework for Rational Analysis of Mobile Education (FRAME Model) by Koole (2009) in Figure 3, to depict the environment of m-learning which can be offered to $L 2$ teaching and learning. The intersections of three distinct perspectives: device (mobile technologies), learner (human learning capacities) and social (social interaction) form the "mobile learning". This mobile education framework is clearly of value to the formation of the MASLL framework.

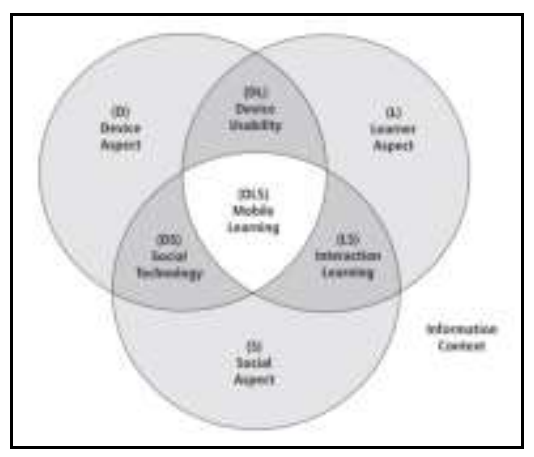

Figure 3. Framework for Rational Analysis of Mobile Education (FRAME)

The device, learner and social aspects in the FRAME Model take into consideration the following characteristics: 
i. Device aspect refers to features of the mobile devices - their physical characteristics, input and output capabilities, storage capacity, processor speed and error rates.

ii. Learner aspect signifies the distinct features of an individual learner - his or her cognitive abilities, memory, learning preferences, willingness to learn, and motivation level.

iii. Social aspect points to the features required for conversation, cooperation and social interaction - meaning sharing and respecting social-cultural differences paving the way for congenial interaction.

The characteristics of the FRAME model run parallel with the L2 acquisition pedagogies, hence it creates a situated learning for social and cultural practices that people bring to the use of tools (in this study referring to mobile phones) they share (Russell, 2002).

\section{Research Methodology}

\section{Research Design and Appropriateness}

This study employs a $2 \times 2$ quasi-experimental design study to investigate the effectiveness of auditory stimuli for the speaking acquisition of a L2, in two different modes of presentation. A sample of 30 middle-year school students from a Malaysian International school participated in a pilot study.

To observe the different effects caused by the independent variables (auditory-visual stimuli versus auditory stimuli) during the interface-acquisition phase, this study had both a control and an experimental group, which helped to measure the potential effects of intervention by assessing the results from the pretest and post-test, using the social networking messaging application - WeChat.

The possible external (i.e. one treatment per group for multiple-treatment interference control, intervention conducted one week after sensitisation of control due to pre-test), and internal threats (i.e. cross-validation for homogenous sample, new topic in intervention for maturity control) were identified and taken into account in order to increase the validity of the research.

The target population were CSL beginners, who own smart phones with Internet subscriptions, aged between 12-15 years old. Due to limited samples being available, and the fact that only an incomplete and unstructured profile can be found for CSL learning in Malaysia, a non-random sampling and purposive strategy was employed for the selection of states, schools and target population.

In addition, in order ensure the speaking proficiency level of samples was homogeneous; a cross-validation approach was taken by using teachers' input in the grouping and learners' self-assessments.

\section{Research Procedures \& Instruments}

Learners went through a two-week experimental study, during school lessons. Pretest was done a week before intervention and post-test, for maturity threat control. 
After 100 minutes of intervention (learning session), post-test was carried out immediately. Instruments to measure speaking performance were validated by five CSL teachers, with teaching experience ranging from 5-20 years.

\section{Results}

Findings from this pilot study show that learners with auditory stimuli performed better than learners with auditory and visual stimuli. Table 3 illustrates the descriptive statistics of speaking scores in pre-test and post-test.

Table 3

Descriptive statistics of speaking scores in two different treatment modes

\begin{tabular}{|c|c|c|c|c|}
\hline \multirow{2}{*}{$\begin{array}{l}\text { Treatment } \\
\text { Mode }\end{array}$} & & \multicolumn{2}{|c|}{ Score } & \multirow{2}{*}{ Gain Score } \\
\hline & & Pre-test & Post-test & \\
\hline \multirow{3}{*}{$\begin{array}{c}\text { Auditory + } \\
\text { Visual Stimuli }\end{array}$} & $\mathrm{N}$ & 15 & 15 & 15 \\
\hline & Mean & 34.20 & 45.20 & 11.00 \\
\hline & $\begin{array}{l}\text { Standard } \\
\text { Deviation }\end{array}$ & 7.26 & 7.14 & 2.673 \\
\hline \multirow{3}{*}{$\begin{array}{l}\text { Auditory } \\
\text { Stimuli }\end{array}$} & $\mathrm{N}$ & 15 & 15 & 15 \\
\hline & Mean & 35.20 & 51.07 & 15.87 \\
\hline & $\begin{array}{l}\text { Standard } \\
\text { Deviation }\end{array}$ & 7.74 & 8.14 & 5.111 \\
\hline \multirow{3}{*}{ Total } & $\mathrm{N}$ & 30 & 30 & 30 \\
\hline & Mean & 34.70 & 43.20 & 13.43 \\
\hline & $\begin{array}{l}\text { Standard } \\
\text { Deviation }\end{array}$ & 7.391 & 8.10 & 4.71 \\
\hline
\end{tabular}

Results in Table 3 indicate there were some increases in the mean gain scores of speaking proficiency in both groups, after receiving treatments of MASLL learning. Learners with auditory stimuli (AS) however outscored the learners with auditory-visual stimuli (AVS) with a difference of 4.87. Therefore the AS group attained higher mean scores than the AVS group in the speaking proficiency (11.00 and 15.87 respectively).

This reveals that learners who focussed on auditory stimuli during the interface-acquisition phase performed better in speaking, when compared with learners who focussed on both the visual and auditory stimuli. From the analyses of gain scores, it can therefore be concluded that to acquire the speaking proficiency of a $L 2$, the rehearsal/training of the auditory channels had to be prioritised, especially during the interface-acquisition phase. Educators should concentrate on providing more auditory stimuli when the goal of learning is to equip the learners to acquire the speaking skills of a L2. Visual stimuli are helpful for clarification or deep learning, but the articulation of sounds for quick mental representation (images) is needed for fluency and accuracy in speaking a L2. 


\section{Discussion}

Results from pilot study suggest that to enhance speaking skills acquisition, learners must utilise their auditory sensory memory for full attention (also called "sensorymotor-training") in working memory, as it will allow for a cross-channel representation process. This however only applies at the transition phase from interface to acquisition training, as postulated by McLaughlin, Rossman, and McLoad (1983) and Krashen (1981).

From the information processing perspective, the episodic buffer in the central executive will activate the episodic LTM by pushed output and rehearsal activities (as shown in Figure 1). This is to bind information from a number of sources into coherent episodes, and such episodes are assumed to be retrievable consciously. Though long-term memory can hold a large amount of knowledge (as explained by Mayer, 2009), in order to actively think about the material it contains, the knowledge must be brought back into the working memory (as indicated by the arrow from long-term memory to working memory). The rationale for the double arrows (for both the rehearsal and episodic buffer) are the active processes for speaking skills acquisition, from controlled to automaticity. The rationale for this rehearsal is due to the fact that information that we hear in phonological form fades away in seconds, (Baddeley, Gathercole, \& Pappagno, 1998), therefore the articulatory rehearsal is indeed crucial, particularly for L2 speaking acquisition.

Without denying the importance of visual stimuli, both the visual and auditory sensory is important during the learning phase (as suggested in Mayer's Cognitive Theory of Multimedia Learning); however when the purpose of learning is to acquire the language skills, the switching from controlled to automaticity is crucial; therefore the training (rehearsal) on one sensory stimuli has to be prioritised.

\section{Conclusion}

The acquisition of skills in language is not considered a success if a learner cannot accomplish the task automatically using the target language. Speaking a L2 is different from a L1; the L2 learners need to retrieve and rehearse the target language actively for auditory-motor-training, as to ultimately understand and converse in the language accurately and fluently without depending on the visual stimuli (mouth, body language, written text, images). It is apparent from this investigation that during the auditory sensory system processes, learners experience the interface process from controlled to automaticity in L2 speaking skills, without having to depend on the written notes, yet are able to speak the TL fluently and accurately. In other words, the cross-mental representation process is the key to achieve acquisition, which requires appropriate rehearsal training - the sensorymotor training in the auditory channels.

A larger sample of population will be carried out in the near future to further validate the efficiency of auditory stimuli as a whole. To L2 teachers and instructional designers, this framework provides a cognitive learning explanation about how learners acquire the speaking skills from the perspective of the 
information processing system, with the aid of multimedia in a mobile learning environment. Technologies in mobile phones today can be utilised for speaking skills teaching and learning due to their retention and interaction features in voice messaging. For L2 learners, it is suggested that a focus on the auditory-motortraining, and less dependence on written text, will aid the speaking of a L2. Visual stimuli are very useful at the beginning stage of learning, but not for the purpose of acquiring speaking skills (which is very similar to speaking through a mobile phone, where no visual clues are provided).

\section{References}

Abdous, M., Camarena, M. M., \& Facer, B. R. (2009). MALL technology: Use of academic podcasting in the foreign language classroom. ReCALL, 21(1), 76-95.

Al-Jarf, R. (2012). Mobile technology and student autonomy in oral skill acquisition. In J. Díaz-Vera (Ed.), Left to my own devices: Learner autonomy and mobileassisted language learning innovation and leadership in English language teaching (pp. 105-130). Bingley, UK: Emerald Group. Retrieved from http://dx.doi.org/

Baddeley, A. (1992). Working memory. Science, 255(5044), 556-559.

Baddeley, A.D., Gathercole, S., \& Pappagno, C. (1998). The phonological loop as a language learning device. The Psychological Review, 105, 158-173.

Baddeley, A. D. (2000). The episodic buffer: a new component of working memory? Trends in Cognitive Sciences, 4(11), 417-423. Retrieved from http://www.ncbi.nlm.nih.gov/pubmed/11058819

Baddeley, A. D., \& Hitch, G. J. (2000). Development of working memory: should the Pascual-Leone and the Baddeley and Hitch models be merged? Journal of Experimental Child Psychology, 77(2), 128-137. http://doi.org/10.1006/ jecp.2000.2592

Basoglu, E., \& Akdemir, O. (2010). A comparison of undergraduate students' English vocabulary learning: Using cell phones and flash cards. Turkish Online Journal of Educational Technology, 9(3), 1-7.

Cavus, N., \& Ibrahim, D. (2009). m-Learning: An experiment in using SMS to support learning new English language words. British Journal of Educational Technology, 40(1), 78-91.

Chang, C. K, \& Hsu, C. K. (2011). A mobile-assisted synchronously collaborative translation-annotation system for English as a foreign language (EFL) reading comprehension. Computer-Assisted Language Learning, 24(2), 155-180.

Choi, E. J., \& Jeong, D-B., (2010). The effects of college students' vocabulary learning by using mobile LMS lesson. Multimedia-Assisted Language Learning, 13(3), 279-302.

Godwin-Jones, R. (2005). Emerging technologies: Messaging, gaming, peer-to-peer sharing: Language learning strategies \& tools for the millennial generation. Language Learning \& Technology, 9(1), 17-22.

Hegelheimer, V., \& O'Bryan, A. (2009). Mobile technologies and language education. In M. Thomas (Ed.). Handbook of research on Web 2.0 and second language learning (pp. 331-349). Hershey, PA: Information Science Reference. 
Ellis, R. (2005) Principles of instructed language learning. System 33, 209-224.

Jiang, X. L. \& Cohen, A. D. (2012). A critical review of research on strategies in learning Chinese as both a second and foreign language. Studies in second language learning and teaching, 2(1), 9-43.

Kinash, S., Brand, J., \& Mathew, T. (2012). Challenging mobile learning discourse through research : Student perceptions of Blackboard Mobile Learn and iPads, 28(4), 639-655.

Koole, M. L. (2009). A model for framing mobile learning. In M. Alley (Ed.), Mobile learning: Transforming the delivery of education and training (pp. 25-47). Athabasca University, Canada: AU Press.

Krashen, S. D. (1981). Second language acquisition and second language learning. US: University of Southern California.

Leow, C. K., Wan Ahmad Jaafar, W. Y., \& Samsudin, Z. (2014a). Feasibility of mobile chat room in enhancing oral communicative skills amongst learners of Chinese as a second Language. Proceedings of the Global Conference on Language Practice \& Information Technology 2014. Sabah, Malaysia.

Leow, C. K., Wan Ahmad Jaafar, W. Y., \& Samsudin, Z. (2014b). A preliminary investigation: Potential of implementing mobile learning to foster oral communicative skills among Chinese as foreign language learners. . The Asian Conference on Language Learning, Osaka, Japan, 315-325. Retrieved from http://iafor.org/Proceedings/ACLL/ACLL2014_proceedings.pdf.

Lu, M. (2008). Effectiveness of vocabulary learning via mobile phone. Journal of Computer Assisted Learning, 24(6), 515-525.

Malaysian Ministry of Higher Education. (2007). The National Higher Education Strategic Plan Beyond 2020. The Ministry of Higher Education Malaysia Press. Retrieve from http://www.mohe.gov.my/transformasi/images/1_bi.pdf.

Malaysian Communication and Multimedia Commission (2013). Annual Report 2013. Retrieved from http://www.skmm.gov.my/skmmgovmy/media/General/ pdf/MCMC-AR_ENG_2013.pdf.

Malaysian Communication and Multimedia Commission (2014). Hand Phone Users Survey 2014. Retrieved from http://www.skmm.gov.my/skmmgovmy /media/General/pdf/Hand-Phone-User2014.pdf.

Mayer, R. E. (2009) Multimedia learning (2nd ed.). Santa Barbara, USA: Cambridge University Press.

Mayer, R. E. (2014). The Cambridge handbook of multimedia learning (2nd ed.). USA: Cambridge University Press.

McLaughlin, B., Rossman, T., \& McLoad, B. (1983). Second language learning: an information-processing perspective. Language Learning, 33(2), 135-158.

Nation, I. S. P. (2007). The Four Strands. Innovation in language learning and teaching, 1(1), 2-13. United Kingdom, UK: Routledge. Retrieved from http://doi.org/10.2167/illt039.0

Paivio, A. (1986). Mental representations. New York: Oxford University Press.

Russell, D. (2002). Looking beyond the interface: activity theory and distributed learning. In M. Lea, \& K. Nicoll (Eds), Distributed learning: Social and cultural approaches to practice, design: Scenario-based design of collaborative systems. Amsterdam, The Netherlands: IOS press. 
Wang, Y., Wu, M. \& Wang, H. (2009). Investigating the determinants and age and gender differences in the acceptance of mobile learning. British Journal of Educational Technology, 40(1), 92-118.

Wu, T., Sung, T., Huang, Y., Yang, C., \& Yang, J-C. (2011) Ubiquitous English learning system with dynamic personalized guidance of learning portfolio. Educational Technology \& Society, 14(4), 164-180. Retrieved from http//www.ifets.info.

Xie, T. W \& Yao, T. C. (2012). Technology in Chinese language teaching and learning. In Everson. E., \& Xiao, Y (Eds.), Teaching Chinese as a foreign language: Theories and applications (pp. 151-172). Boston: Cheng \& Tsui Company. 